\title{
TRATAMENTO ANAERÓBIO DE ÁGUAS RESIDUÁRIAS DO BENEFICIAMENTO DE CAFÉ POR VIA ÚMIDA EM REATORES UASB EM DOIS ESTÁGIOS
}

\author{
MARCELO BRUNO ${ }^{1}$, ROBERTO A. DE OLIVEIRA ${ }^{2}$
}

\begin{abstract}
RESUMO: Neste trabalho, avaliou-se a eficiência do tratamento de águas residuárias do beneficiamento de café por via úmida em reatores anaeróbios de fluxo ascendente com manta de lodo (UASB), em dois estágios, em escala de bancada, submetidos a tempos de detenção hidráulica (TDH) de 4,0; 5,2 e 6,2 dias e cargas orgânicas volumétricas (COV) de 5,8; 3,0 e 3,6 g DQO total (L d) ${ }^{-1}$, no primeiro reator (R1), e TDH de 2,0; 2,6 e 3,1 dias e COV de 5,8; 0,5 e 0,4 g DQO total (L d) ${ }^{-1}$, no segundo reator (R2). Os valores médios de DQO do afluente variaram de 15.440 a $23.040 \mathrm{mg} \mathrm{O}_{2} \mathrm{~L}^{-1}$. As eficiências médias de remoção de DQO total e SST foram de 66 a $98 \%$ e de 93 a $97 \%$, respectivamente, nos reatores UASB, em dois estágios. O teor médio de metano no biogás variou de 69 a $89 \%$, no reator $\mathrm{R} 1$, e de 52 a $73 \%$, no reator R2. A produção volumétrica máxima de metano de $0,708 \mathrm{~L} \mathrm{CH}_{4}\left(\mathrm{~L}\right.$ reator d) ${ }^{-1}$ foi obtida com COV de 3,6 g DQO $(\mathrm{L} \mathrm{d})^{-1}$ e TDH de 6,2 d, no reator R1. Os valores médios de $\mathrm{pH}$ variaram de 4,7 a 7,7 e de 4,9 a 8,0 nos efluentes dos reatores R1 e R2, respectivamente. As concentrações de ácidos voláteis totais nos efluentes mantiveram-se estáveis com valores inferiores a $100 \mathrm{mg} \mathrm{L}^{-1}$, com TDH de 5,2 e 6,2 dias, no reator R1, e TDH de 2,6 e 3,1 dias, no reator R2. As concentrações médias de fenóis totais no afluente variaram de 80 a $97 \mathrm{mg} \mathrm{L}^{-1} \mathrm{e}$ as eficiências médias de remoção nos reatores UASB, em dois estágios, foram de 72 a 90\%.
\end{abstract}

PALAVRAS-CHAVE: digestão anaeróbia, fenóis, águas residuárias de café despolpado, carga orgânica volumétrica.

\section{ANAEROBIC TREATMENT OF WASTEWATER FROM COFFEE PULPING IN UPFLOW ANAEROBIC SLUDGE BLANQUET (UASB) IN TWO STAGES}

\begin{abstract}
In this work, it was evaluated the efficiency of two stage up flow anaerobic sludge blanquet (UASB) reactors, in bench scale, treating a liquid effluent from the coffee pulping, submitted to hydraulic detention time (HDT) of 4.0; 5.2 and 6.2 days, resulting in organic loading rate (OLR) of 5.8; 3.6 and $3.0 \mathrm{~g} \mathrm{COD}(\mathrm{L} \mathrm{d})^{-1}$ in the first reactor $(\mathrm{R} 1)$ and HDT of 2.0; 2.6 and 3.1 days with OLR of $5.8 ; 0.5$ and $0.4 \mathrm{~g}$ DQO total $(\mathrm{L} \mathrm{d})^{-1}$ in the second reactor $(\mathrm{R} 2)$. The medium values of total COD affluent varied from 15,440 to $23,040 \mathrm{mg} \mathrm{O}_{2} \mathrm{~L}^{-1}$. The medium values of removal efficiencies of total COD and TSS varied from 66 to $98 \%$ and 93 to $97 \%$, respectively, in the system of treatment with the UASB reactors in two stages. The content of methane in the biogas varied from 69 to $89 \%$ in the R1 and from 52 to $73 \%$ in the R2. The maximum volumetric methane production of $0.708 \mathrm{~L} \mathrm{CH}_{4}\left(\mathrm{~L}\right.$ reactor d) ${ }^{-1}$ was obtained with OLR of $3.6 \mathrm{~g}$ total COD (L reactor d) ${ }^{-1}$ and HDT of 6.2 days in the R1. Average $\mathrm{pH}$ values ranged from 4.7 to 7.7 and 4.9 to 8.0 in the effluents of R1 and R2, respectively. Total volatile acids concentrations was kept below $100 \mathrm{mg} \mathrm{L}^{-1}$ with HDT of 5.2 and 6.2 days in the R1 and HDT of 2.6 and 3.1 days in the R2. The medium values of total phenols of affluent ranged from 80 to $97 \mathrm{mg} \mathrm{L}^{-1}$ and the average removal efficiencies ranged from 72 to $90 \%$ in the UASB reactors in two stages.
\end{abstract}

KEYWORDS: anaerobic digestion, phenols, coffee wastewater, organic loading rate.

\footnotetext{
${ }^{1}$ Químico, Doutorando em Microbiologia Agropecuária, UNESP - Jaboticabal - SP.

${ }^{2}$ Eng ${ }^{\mathrm{o}}$ Agrônomo e Tecnólogo em Construção Civil, Prof. Dr., Departamento de Engenharia Rural, UNESP - Jaboticabal - SP, raoder@fcav.unesp.br

Recebido pelo Conselho Editorial em: 22-2-2007
}

Aprovado pelo Conselho Editorial em: 22-4-2008 


\section{INTRODUÇÃO}

Grande parte das atividades agroindustriais desenvolvidas no Brasil e no mundo tem como um dos fatores limitantes à produção a geração de resíduos e de efluentes. A cafeicultura, no Brasil, com produção estimada, na safra 2005/2006, de 40,6 milhões de sacas (IBGE, 2006), pode, no processamento, ocasionar a liberação de resíduos sólidos e líquidos. Apenas $6 \%$ do conteúdo de uma cereja de café colhida transforma-se em bebida (PULGARIN et al., 1991).

No tocante ao processamento dos grãos pós-colheita, há duas metodologias que podem ser empregadas: por via seca, secando-se os frutos íntegros, ou por via úmida, propiciando a secagem dos frutos sem casca e sem mucilagem, ou seja, dos grãos descascados e despolpados, respectivamente. No processamento do café por via seca, utiliza-se da água apenas nos lavadores para a separação de impurezas, contribuindo com pequena parte dos resíduos gerados. Na via úmida, o maior problema do despolpamento é a grande quantidade de água utilizada e a alta carga poluidora gerada, ou seja, 4 litros de água residuária por litro de café lavado, descascado e despolpado com DBO de 1.840 a $14.340 \mathrm{mg} \mathrm{L}^{-1}$ (MATOS \& LO MÔNACO, 2003).

No Brasil, o despolpamento mecânico está sendo a técnica mais empregada. Consiste na utilização de despolpadores, que são equipamentos verticais, de fluxo ascendente, que possuem um helicóide, movimentando o grão de café em um cilindro canelado, com pequena vazão de água (150 a $200 \mathrm{~L} \mathrm{~h}^{-1}$ ). Nesse equipamento, são retiradas de 80 a $90 \%$ da goma, o que facilita o trabalho de secagem (PINTO, 2001). De acordo com DELGADO \& BAROIS (1999), citados por LO MÔNACO et al. (2002), no processamento por via úmida tradicional, são geradas aproximadamente 3 toneladas de subprodutos e requeridas 4 toneladas de água para produzir 1 tonelada de grão processado, além de cascas e polpa úmida.

O processo de lavagem e de despolpa do café reduz os gastos de energia durante a secagem e melhora a qualidade de bebida, agregando valor ao mesmo. Entretanto, a água residuária desse processo é rica em material orgânico em suspensão e constituintes orgânicos em solução (MATOS \& LO MÔNACO, 2003). Contêm quantidade alta de sólidos sedimentáveis, açúcares (frutose, glicose e galactose), proteínas, polifenóis (ácidos clorogênico e caféico, taninos e cafeína), pequenas quantidades de corantes naturais (antocianinas) e DQO alta, da ordem de $34.460 \mathrm{mg} \mathrm{L}^{-1}$. Em torno de 8\% da DQO corresponde a compostos fenólicos (ZAMBRANO \& ISAZA, 1998).

Essas águas residuárias lançadas nos cursos d'água prejudicam seu uso e formam zonas anaeróbias, com liberação de metano, fenóis e ácido sulfídrico, cujo odor desagradável afeta as populações ribeirinhas (PINTO, 2001). Os fenóis são tóxicos, carcinogênicos, mutagênicos e teratogênicos, podem inibir o crescimento dos microrganismos nos processos biológicos de tratamento e, em concentrações acima de $1 \mathrm{mg} \mathrm{L}^{-1}$, afetam a vida aquática (VEERESH et al., 2005).

A digestão anaeróbia é uma das melhores alternativas para o tratamento de subprodutos altamente poluidores, como resíduos sólidos, efluentes da agroindústria, esgoto sanitário doméstico e dejetos de animais. A produção de metano e de efluente estabilizado é muito importante na digestão anaeróbia e pode ser utilizada como combustível e biofertilizante, respectivamente. Há muito conhecido, o processo anaeróbio, nas últimas décadas, teve importantes avanços no conhecimento de seus fundamentos, principalmente na microbiologia e na concepção dos reatores. Para o tratamento de efluentes industriais com alto teor de matéria orgânica, têm sido aplicados os reatores biológicos anaeróbios, em virtude das vantagens técnicas e econômicas, e um dos principais é o reator anaeróbio de fluxo ascendente com manta de lodo (UASB). No tratamento anaeróbio, ocorre elevada remoção de material orgânico suspenso e solúvel, inclusive substâncias tóxicas, como os fenóis, porém a remoção de nutrientes é baixa (CHERNICHARO, 2007; GERARDI, 2003; METCALF \& EDDY, 2003, SPEECE, 1996; VEERESH et al., 2005).

Uma limitação do tratamento de águas residuárias com concentrações elevadas de sólidos orgânicos biodegradáveis, como as águas residuárias do beneficiamento de café por via úmida, em reatores anaeróbios em um estágio (BELLO-MENDOZA \& CASTILLO-RIVERA, 1998; LUIZ et al., 2004; SILVA \& CAMPOS, 2005) é a hidrólise lenta ou a rápida acidificação, com produção de 
grandes quantidades de ácidos graxos voláteis, os quais podem prejudicar a atividade das arquéias metanogênicas.

O uso de sistemas de tratamento anaeróbio em dois estágios pode melhorar a estabilidade, facilitar a operação, possibilitar a redução do volume dos reatores e reduzir os problemas com a duplicação excessiva de bactérias acidogênicas e conseqüente diminuição das arquéias metanogênicas. A grande vantagem do uso do processo anaeróbio em dois estágios é a acomodação no reator do primeiro estágio das variações das cargas orgânicas do afluente, permitindo a aplicação de cargas constantes no segundo estágio. Além disso, visa à otimização do tempo de retenção celular, melhoria das condições ambientais e de nutrição, fornecimento de substratos específicos e controle da toxicidade (BOUALLAGUI et al., 2004; GERARDI, 2003; HAANDEL \& LETTINGA, 1994)

Portanto, neste trabalho, avaliou-se a eficiência de reatores anaeróbios de fluxo ascendente com manta de lodo (UASB) em dois estágios, no tratamento de águas residuárias do beneficiamento de café por via úmida, com DQO total variando de 4.000 a $36.000 \mathrm{mg} \mathrm{O}_{2} \mathrm{~L}^{-1}$, com diferentes tempos de detenção hidráulica (TDH) e cargas orgânicas volumétricas (COV).

\section{MATERIAL E MÉTODOS}

O trabalho foi realizado no Laboratório de Biodigestão Anaeróbia e Biomassa do Departamento de Engenharia Rural, da Faculdade de Ciências Agrárias e Veterinárias da Universidade Estadual Paulista - UNESP, Câmpus de Jaboticabal, cujas coordenadas geográficas são $21^{\circ} 15^{\prime} 22^{\prime}$ ' latitude sul; 48 $18^{\prime} 58^{\prime}$ ' longitude oeste e $575 \mathrm{~m}$ de altitude. O clima da região, segundo classificação de Köeppen, é Cwa (subtropical úmido, seco no inverno e com chuva no verão), com precipitação média anual de $1.300 \mathrm{~mm}$ e temperatura média anual de $21^{\circ} \mathrm{C}$.

A unidade experimental, com o sistema de tratamento anaeróbio em dois estágios (Figura 1), foi constituída por dois reatores UASB, em escala de bancada, instalados em série, com volume de $20 \mathrm{~L}$ (primeiro estágio, R1) e $10 \mathrm{~L}$ (segundo estágio, R2), construídos com tubos e conexões de PVC, com diâmetros de 150 e $100 \mathrm{~mm}$ e com altura de 1,50 e 1,30 m, respectivamente. O separador de fases não-convencional na forma de $\mathrm{Y}$, com ângulo de $45^{\circ} \mathrm{em}$ relação à vertical, foi construído conforme proposto por HAANDEL et al. (1999). O efluente do R1 foi conduzido até o R2 por gravidade através de tubo de PVC interligando os reatores. Foi utilizado um tanque de $5 \mathrm{~L}$ para o armazenamento do afluente do reator UASB (R1). Para o monitoramento da produção do biogás, foram instalados um gasômetro de PVC no R1 e um gasômetro de alumínio no R2 (Figura 1).

O afluente utilizado para a alimentação contínua dos reatores foi a água residuária proveniente da lavagem e da despolpa dos grãos de café da Fazenda Monjolinho, localizada na cidade de Altinópolis - SP, com pH médio de 4,2; concentração média de sólidos suspensos totais (SST) de 2.978 a $3.590 \mathrm{mg} \mathrm{L}^{-1}$ e com DQO total média de 15.440 a $23.040 \mathrm{mg} \mathrm{O}_{2} \mathrm{~L}^{-1}$ (Tabela 1).

A água residuária do beneficiamento de café por via úmida foi coletada três vezes em épocas distintas, no começo (mês de junho), meio (mês de julho) e final (mês de agosto) da safra, e armazenada sob refrigeração (congelamento) durante todo o período da pesquisa. Após aclimatação à temperatura ambiente, a água residuária era peneirada (peneira de náilon com malha quadrada de $1,5 \times 1,5 \mathrm{~mm}$ ), visando à separação dos sólidos grosseiros, como cascas e pedaços de grãos de café, evitando, assim, o entupimento da linha de alimentação do R1.

Depois de peneirada, a água residuária era neutralizada com $\mathrm{NaOH}$ para a obtenção de $\mathrm{pH}$ em torno de 7,0 e, em seguida, era colocada no tanque de armazenamento, na quantidade necessária para um dia de alimentação, constituindo o afluente do R1 do sistema de tratamento anaeróbio com os reatores UASB em dois estágios.

O experimento foi dividido em três ensaios, variando-se o tempo de detenção hidráulica (TDH) e a carga orgânica volumétrica (COV) aplicados nos reatores UASB (R1 e R2), conforme descrito na Tabela 1. 


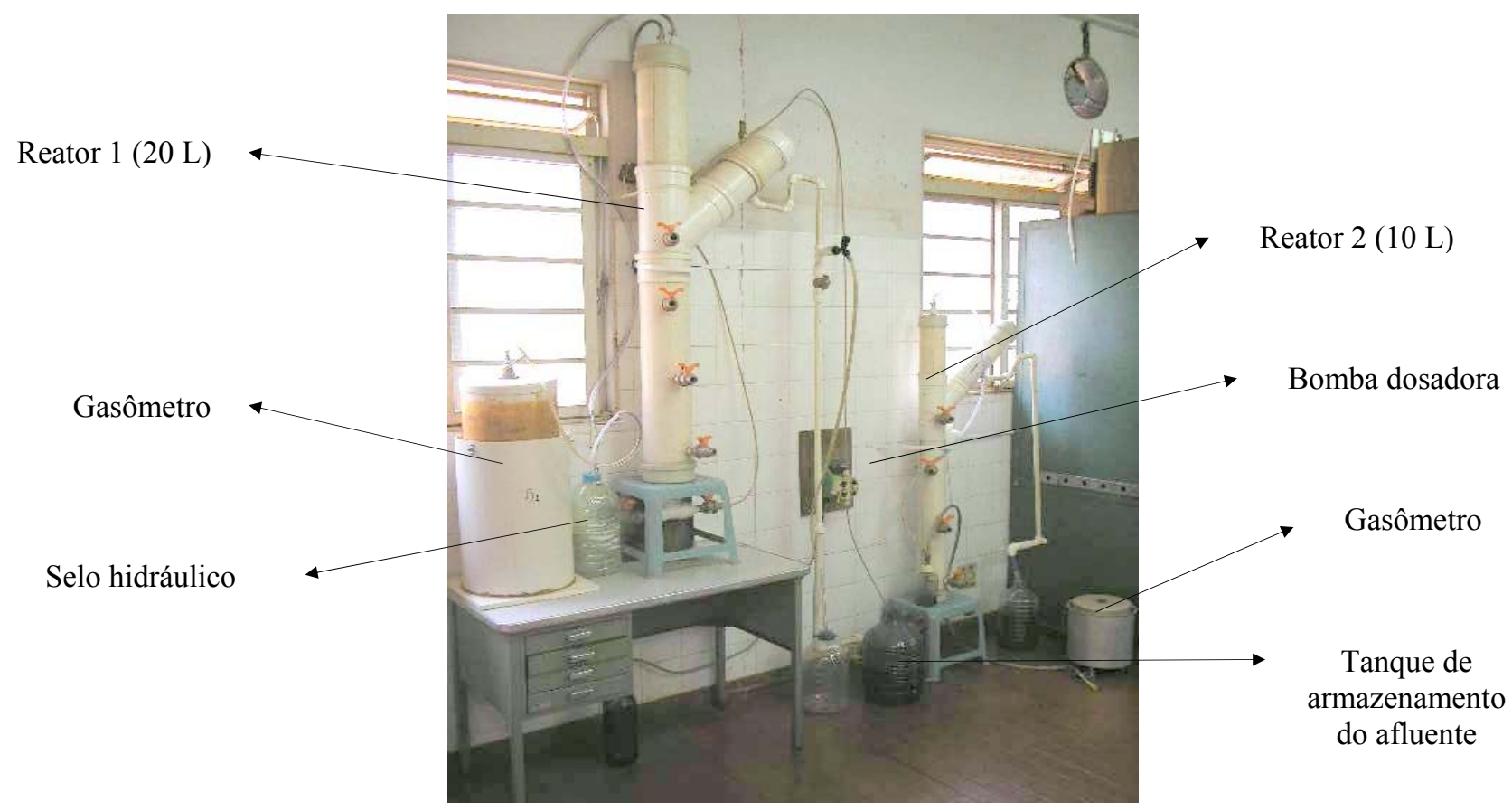

FIGURA 1. Sistema de tratamento anaeróbio composto de reatores UASB em dois estágios, bomba dosadora, tanque de armazenamento de afluente, selos hidráulicos e gasômetros.

Anaerobic treatment system composed of UASB reactors in two stages, dosing pump, storing tank of affluent, hydraulic seals and gas meters.

TABELA 1. Condições operacionais impostas aos reatores UASB (R1 e R2), em dois estágios, e características do afluente nos ensaios 1;2 e 3. Operational conditions of UASB reactors ( $R 1$ and $R 2)$ in two stages and affluent characteristics in the trials $1 ; 2$ and 3.

\begin{tabular}{cccccccccc}
\hline \multirow{2}{*}{ Ensaio } & $\begin{array}{c}\text { Duração } \\
(\mathrm{d})\end{array}$ & \multicolumn{2}{c}{$\begin{array}{c}\mathrm{TDH} \\
(\mathrm{d})\end{array}$} & $\begin{array}{c}\mathrm{SST} \\
\left(\mathrm{mg} \mathrm{L}^{-1}\right)\end{array}$ & $\begin{array}{c}\mathrm{DQO} \\
\left(\mathrm{mg} \mathrm{O}_{2} \mathrm{~L}^{-1}\right)\end{array}$ & $\begin{array}{c}\mathrm{COV} \\
(\mathrm{g} \text { DQO }\end{array}$ total $\left.(\mathrm{L} \mathrm{d})^{-1}\right)$ & \multicolumn{2}{c}{$\begin{array}{c}\mathrm{CHV} \\
\left(\mathrm{h}^{-1}\right)\end{array}$} \\
\cline { 3 - 10 } & $\mathrm{R} 1$ & $\mathrm{R} 2$ & $\mathrm{R} 1$ & $\mathrm{R} 1$ & $\mathrm{R} 1$ & $\mathrm{R} 2$ & $\mathrm{R} 1$ & $\mathrm{R} 2$ \\
\hline 1 & 35 & 4,0 & 2,0 & 3.590 & 23.040 & 5,8 & 5,8 & 0,25 & 0,50 \\
2 & 45 & 6,2 & 3,1 & 2.978 & 21.950 & 3,6 & 0,4 & 0,16 & 0,32 \\
3 & 45 & 5,2 & 2,6 & 3.390 & 15.440 & 3,0 & 0,5 & 0,20 & 0,40 \\
\hline
\end{tabular}

TDH - tempo de detenção hidráulica; COV - carga orgânica volumétrica; SST - sólidos suspensos totais; DQO demanda química de oxigênio; CHV - carga hidráulica volumétrica.

O experimento foi iniciado com o ensaio 1, com TDH de 4 dias no R1, e teve duração de somente 35 dias, em virtude do colapso de ambos os reatores, a partir dos 15 dias de operação.

Assim, no ensaio 2, o TDH no R1 foi aumentado para 6,2 dias e, no ensaio 3, reduzido para 5,2 dias. A duração desses ensaios foi de 45 dias, constatando-se a ocorrência de estabilidade quando os valores médios de eficiências de remoção e de produção volumétrica de metano, nos reatores UASB, em dois estágios $(\mathrm{R} 1+\mathrm{R} 2)$, apresentaram coeficientes de variação inferiores a $10 \%$ por, pelo menos, quatro semanas consecutivas.

Para a partida do sistema de tratamento, foi usado, como inóculo, lodo proveniente de reatores UASB tratando águas residuárias de suinocultura, operados com TDH de 18 h e COV de $34 \mathrm{~g}$ DQO total $(\mathrm{L} \mathrm{d})^{-1}$, nos quais a percentagem de $\mathrm{CH}_{4}$ no biogás era de $74 \%$, e a produção volumétrica era de $1,325 \mathrm{~L} \mathrm{CH}_{4}$ (L reator d) ${ }^{-1}$. Ao $\mathrm{R} 1$ foi adicionado lodo suficiente para preencher $50 \%$ de seu volume, ou seja, $10 \mathrm{~L}$, e ao R2 foram adicionados $5 \mathrm{~L}$ de lodo com concentrações de sólidos totais (ST) e voláteis (SV) de 55,1 e 44,2 $\mathrm{g} \mathrm{L}^{-1}$, respectivamente. A carga orgânica no lodo (COL) do R1, durante a partida do ensaio 1 , foi de $0,17 \mathrm{~g}$ DQO $\left(\mathrm{g} \mathrm{SV} \mathrm{d}^{-1}\right.$. 
O mesmo procedimento foi repetido no ensaio 2, em virtude do colapso dos reatores UASB ao final do ensaio 1, com a acidificação e degradação do lodo, o qual foi substituído por lodo de inóculo similar ao utilizado no ensaio 1, com concentrações de ST e SV de 59,1 e 46,2 $\mathrm{g} \mathrm{L}^{-1}$, respectivamente. A COL do R1, durante a partida do ensaio 2, foi de $0,14 \mathrm{~g}$ DQO total ( $\mathrm{g} \mathrm{SV} \mathrm{d})^{-1}$. O lodo presente nos reatores, ao final do ensaio 2, foi mantido no ensaio 3.

As amostras dos efluentes dos reatores R1 e R2 foram coletadas nas torneiras das tubulações de entrada de cada reator. As amostras do afluente do R1 foram coletadas após a neutralização do afluente com $\mathrm{NaOH}$ diretamente no tanque de armazenamento. As amostras dos efluentes dos reatores foram coletadas de maneira a obter amostras compostas, com coleta de aproximadamente $50 \mathrm{~mL}$ a cada 30 minutos, até obter o volume de $400 \mathrm{~mL}$ de efluente de cada reator.

Foram determinados nessas amostras, duas vezes por semana: $\mathrm{pH}$; alcalinidade total (AT); sólidos suspensos totais (SST) e voláteis (SSV); demanda química de oxigênio total (DQO total), de acordo com APHA, AWWA, WPCF (1998). A DQO dissolvida (DQO ${ }_{\text {diss }}$ ) foi determinada duas vezes por semana, e o volume de biogás produzido foi determinado diariamente por meio de medidas nos gasômetros, como descrito por SANTANA \& OLIVEIRA (2005). A composição do biogás foi analisada, a cada 15 dias, por cromatografia gasosa, conforme APHA, AWWA, WPCF (1998). A concentração de ácidos voláteis totais (AVT) foi determinada duas vezes por semana, segundo metodologia descrita por DILALLO \& ALBERTSON (1961).

A concentração de fenóis totais (FT) foi determinada duas vezes por semana, segundo metodologia de Folin-Ciocalteau, descrita por SHAHIDI \& NACZK (1995).

\section{RESULTADOS E DISCUSSÃO}

$\mathrm{O}$ primeiro reator $(\mathrm{R} 1)$ foi alimentado com águas residuárias provenientes do despolpamento de café, com valores médios de SST de 3.590; 2.978 e $3.390 \mathrm{mg} \mathrm{L}^{-1}$; de DQO total de 23.040; 21.950 e $15.440 \mathrm{mg} \mathrm{O}_{2} \mathrm{~L}^{-1}$, e de $\mathrm{DQO}_{\text {diss }}$ de 20.090; 19.190 e $11.610 \mathrm{mg} \mathrm{O}_{2} \mathrm{~L}^{-1}$ nos ensaio 1 ; 2 e 3, respectivamente (Tabela 2). As variações dos valores de DQO total no afluente e nos efluentes dos reatores 1 e 2 estão apresentadas na Figura 2.

TABELA 2. Valores médios e coeficientes de variação (C.V.\%) da DQO total, $\mathrm{DQO}_{\text {diss, sólidos }}$ suspensos totais (SST) e voláteis (SSV) e fenóis totais (FT), em mg L ${ }^{-1}$, nos afluentes e nos efluentes, e carga orgânica volumétrica (COV), em g DQO total ( $\mathrm{L} \mathrm{d})^{-1}$, durante a operação dos reatores UASB (R1 e R2) em dois estágios, nos ensaios 1; 2 e 3. Average values and variation coefficients (VC\%) of total and dissolved chemical oxygen demand (total COD and ${ }_{\text {diss }}$ COD), total and volatile suspended solids (TSS and VSS) and total phenols (TP), in $\mathrm{mg} \mathrm{L}^{-1}$, in the affluents and effluents, and the volumetric organic loading (VOL), in $\mathrm{g}$ total COD $(\mathrm{L} \mathrm{d})^{-1}$, during the operation of UASB reactors ( $R 1$ and $R 2)$ in two stages, in the trials 1; 2 and 3 .

\begin{tabular}{|c|c|c|c|c|c|c|c|c|c|}
\hline \multirow{3}{*}{ Parâmetros } & \multirow{3}{*}{ Afluente } & \multicolumn{2}{|c|}{ Ensaio 1} & \multicolumn{3}{|c|}{ Ensaio 2} & \multicolumn{3}{|c|}{ Ensaio 3} \\
\hline & & \multicolumn{2}{|c|}{ Efluente } & \multirow{2}{*}{ Afluente } & \multicolumn{2}{|c|}{ Efluente } & \multirow{2}{*}{ Afluente } & \multicolumn{2}{|c|}{ Efluente } \\
\hline & & R1 & R2 & & R1 & $\mathrm{R} 2$ & & $\mathrm{R} 1$ & R2 \\
\hline $\mathrm{DQO}_{\text {total }}$ & 23.040 & 11.500 & 9.000 & 21.950 & 1.100 & 420 & 15.440 & 1.240 & 510 \\
\hline $\mathrm{DQO}_{\text {diss }}$ & 20.090 & 10.220 & 8.700 & 19190 & 710 & 320 & 11.610 & 740 & 330 \\
\hline SST & 3.590 & 630 & 226 & 2.978 & 688 & 111 & 3.390 & 220 & 60 \\
\hline SSV & 1.488 & 401 & 155 & 1.296 & 291 & 51 & 1.350 & 100 & 30 \\
\hline FT & 80 & 35 & 23 & 97 & 19 & 10 & 90 & 21 & 11 \\
\hline $\mathrm{COV}$ & - & 5,8 & 5,8 & - & 3,6 & 0,4 & - & 3,0 & 0,5 \\
\hline $\mathrm{DQO}_{\text {total }}$ & 35 & 70 & 82 & 38 & 40 & 42 & 24 & 18 & 18 \\
\hline $\mathrm{DQO}_{\text {diss }}$ & 39 & 75 & 87 & 42 & 57 & 47 & 29 & 34 & 25 \\
\hline CV SST & 50 & 46 & 52 & 30 & 87 & 70 & 42 & 73 & 67 \\
\hline$\% \mathrm{SSV}$ & 70 & 57 & 45 & 54 & 97 & 90 & 46 & 50 & 66 \\
\hline FT & 40 & 45 & 63 & 18 & 34 & 26 & 32 & 35 & 35 \\
\hline $\mathrm{COV}$ & & 37 & 69 & - & 32 & 42 & - & 29 & 35 \\
\hline
\end{tabular}



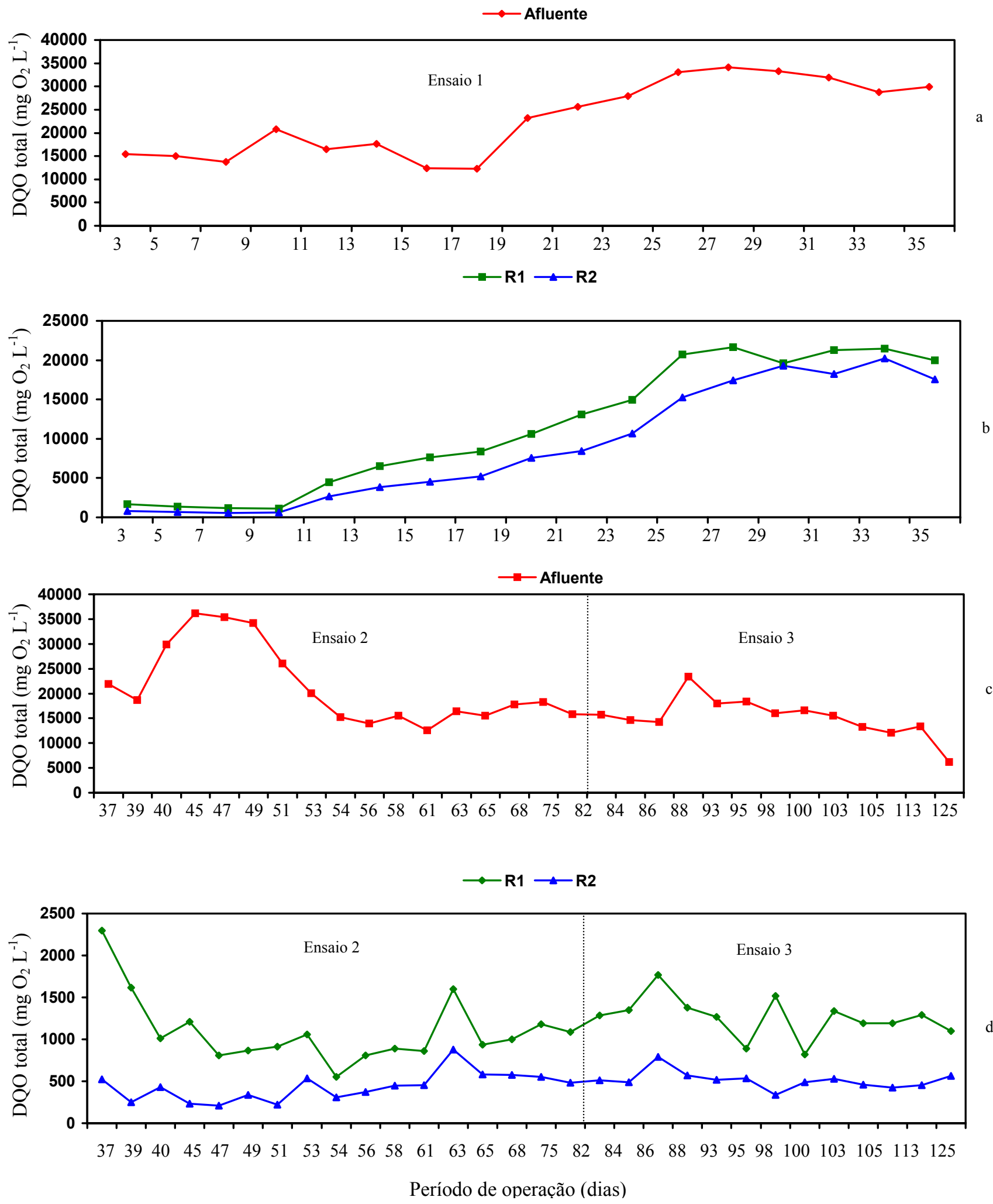

FIGURA 2. Demanda química de oxigênio total (DQO total) do afluente (a e c) e dos efluentes dos reatores UASB em dois estágios (R1 e R2), nos ensaios 1 (b), 2 e 3 (d). Total chemical oxygen demand (total $C O D$ ) in the affluent (a and c) and effluents of UASB reactors (R1 and $R 2)$ in two stages, in the trials 1 (b), 2 and 3 (d).

No decorrer do experimento, houve aumento (do início para o final do ensaio 1) e redução progressiva (a partir do ensaio 2) dos valores da DQO total e dissolvida do afluente, o que pode ser atribuído às variações na quantidade de compostos orgânicos liberados dos frutos do cafeeiro 
durante o processamento, em virtude de alterações de concentração durante a safra e/ou oscilações de massa de frutos processados (por unidade de tempo ou de volume de água utilizada), do início para o final da colheita, com valores máximos no meio da safra.

Os valores médios das cargas orgânicas volumétricas (COV) aplicadas no R1, nos ensaios 1; 2 e 3, foram de 5,8; 3,6 e 3,0 g DQO total ( $\mathrm{L} \mathrm{d})^{-1}$ (Tabela 2), respectivamente. No ensaio 2, a COV diminuiu em virtude da aplicação de TDH maior, para evitar a repetição do colapso ocorrido no ensaio 1. No ensaio 3, embora o TDH tenha sido diminuído, a COV não aumentou porque a DQO do afluente decresceu acentuadamente.

No ensaio 1, ocorreu diminuição do $\mathrm{pH}$ dos efluentes do $\mathrm{R} 1$ e do $\mathrm{R} 2$ após 15 dias de operação, atingindo os menores valores do experimento, $\mathrm{pH}$ de 4,7 e 4,9, respectivamente, comprometendo o desempenho do sistema de tratamento (Tabelas 3 e 4 e Figuras 3a e b). As arquéias metanogênicas têm crescimento ótimo na faixa de $\mathrm{pH}$ entre 6,6 e 7,4, embora possa ocorrer estabilidade na formação de metano em faixa mais ampla, entre 6,0 e 8,0 (CHERNICHARO, 2007).

TABELA 3. Valores médios e coeficientes de variação (C.V.\%) das eficiências de remoção (\%) de DQO total, DQO ${ }_{\text {diss, }}$, sólidos suspensos totais (SST) e voláteis (SSV), e fenóis totais (FT), durante a operação dos reatores UASB (R1 e R2) em dois estágios, nos ensaios $1 ; 2$ e 3. Average values and variation coefficients (VC\%) of the removal efficiencies (in \%) of total and dissolved chemical oxygen demand (totalCOD and diss COD), total and volatile suspended solids (TSS and VSS) and total phenols (TP) during the operation of UASB reactors ( $R 1$ and $R 2)$ in two stages, in the trials $1 ; 2$ and 3.

\begin{tabular}{lccrccc}
\hline \multirow{2}{*}{ Parâmetros } & \multicolumn{2}{c}{ Ensaio 1 } & \multicolumn{2}{c}{ Ensaio 2 } & \multicolumn{2}{c}{ Ensaio 3 } \\
\cline { 2 - 7 } & $\mathrm{R} 1$ & $\mathrm{R} 1+\mathrm{R} 2$ & $\mathrm{R} 1$ & $\mathrm{R} 1+\mathrm{R} 2$ & $\mathrm{R} 1$ & $\mathrm{R} 1+\mathrm{R} 2$ \\
\hline DQO $_{\text {total }}$ & 55 & 66 & 94 & 98 & 91 & 96 \\
DQO $_{\text {diss }}$ & 49 & 63 & 96 & 98 & 93 & 97 \\
$\mathrm{SST}$ & 79 & 93 & 84 & 97 & 93 & 98 \\
$\mathrm{SSV}$ & 70 & 87 & 79 & 95 & 91 & 97 \\
$\mathrm{FT}$ & 55 & 72 & 80 & 90 & 73 & 86 \\
\hline $\mathrm{DQO}$ & 43 & 33 & 3 & 1 & 3 & 2 \\
$\mathrm{DQO}_{\text {total }}$ & 62 & 41 & 2 & 1 & 2 & 1 \\
CV & 15 & 6 & 11 & 2 & 7 & 2 \\
\%ST & 18 & 10 & 15 & 4 & 6 & 3 \\
$\mathrm{SSV}$ & 18 & 7 & 3 & 30 & 11 \\
FT & 31 & 20 & & & & \\
\hline
\end{tabular}

TABELA 4. Valores médios e coeficientes de variação (C.V.\%) do pH, ácidos voláteis totais (AVT em mg $\mathrm{CH}_{3} \mathrm{COOH} \mathrm{L}{ }^{-1}$ ), alcalinidade total ( $\mathrm{AT}$ em $\mathrm{mg} \mathrm{CaCO}_{3} \mathrm{~L}^{-1}$ ), durante a operação dos reatores UASB (R1 e R2) em dois estágios, nos ensaios 1; 2 e 3 . Average values and variation coefficients $(\mathrm{VC} \%)$ of $\mathrm{pH}$, total volatile acids (TVA in $\mathrm{mg}$ $\mathrm{CH}_{3} \mathrm{COOH} \mathrm{L}^{-1}$ ), total alkalinity (TA in $\mathrm{mg} \mathrm{CaCO}_{3} \mathrm{~L}^{-1}$ ), during the operation of UASB reactors ( $R 1$ and $R 2)$ in two stages, in the trials $1 ; 2$ and 3.

\begin{tabular}{|c|c|c|c|c|c|c|c|c|c|}
\hline \multirow{3}{*}{ Parâmetros } & \multicolumn{3}{|c|}{ Ensaio 1} & \multicolumn{3}{|c|}{ Ensaio 2} & \multicolumn{3}{|c|}{ Ensaio 3} \\
\hline & \multirow[t]{2}{*}{ Afluente } & \multicolumn{2}{|c|}{ Efluente } & \multirow[t]{2}{*}{ Afluente } & \multicolumn{2}{|c|}{ Efluente } & \multirow[t]{2}{*}{ Afluente } & \multicolumn{2}{|c|}{ Efluente } \\
\hline & & R1 & $\mathrm{R} 2$ & & $\mathrm{R} 1$ & $\mathrm{R} 2$ & & $\mathrm{R} 1$ & R2 \\
\hline $\mathrm{pH}$ & 7,3 & 5,3 & 5,7 & 7,6 & 7,5 & 7,9 & 7,5 & 7,7 & 8,0 \\
\hline AVT & 791 & 2.035 & 1.840 & 780 & 70 & 85 & 697 & 68 & 47 \\
\hline AT & 1.986 & 1.693 & 1.827 & 1.900 & 3.043 & 3.077 & 1.213 & 2.201 & 2.327 \\
\hline \multirow{3}{*}{$\begin{array}{c}\text { CV } \\
\%\end{array}$} & 8 & 13 & 16 & 8 & 4 & 4 & 5 & 4 & 2 \\
\hline & 27 & 57 & 73 & 14 & 61 & 47 & 27 & 33 & 38 \\
\hline & 40 & 32 & 17 & 30 & 30 & 28 & 16 & 7 & 12 \\
\hline
\end{tabular}


A queda do $\mathrm{pH}$ nos efluentes do $\mathrm{R} 1$ e do $\mathrm{R} 2$, no ensaio 1, foi relacionada com o aumento da concentração de ácidos voláteis totais (AVT) (Tabela 4 e Figura 4a), provocada pelos acréscimos de carga orgânica e de tóxicos (fenóis) no afluente, que ocorreram após os 15 dias de operação (Figuras 2a e 4c). O mesmo não ocorreu nos ensaios 2 e 3, quando os valores de pH (Figura 3a) não foram limitantes para a metanogênese no R1 e no R2, e a sua estabilidade pode ser atribuída aos altos valores de alcalinidade total (AT de 2.201 a $3.077 \mathrm{mg} \mathrm{CaCO}_{3} \mathrm{~L}^{-1}$ ) (Tabela 4). METCALF \& EDDY (2003) citaram que são necessárias concentrações de alcalinidade de 2.000 a $4.000 \mathrm{mg} \mathrm{CaCO} \mathrm{L}^{-1}$ para manter o valor do $\mathrm{pH}$ próximo de 7 em reatores anaeróbios.
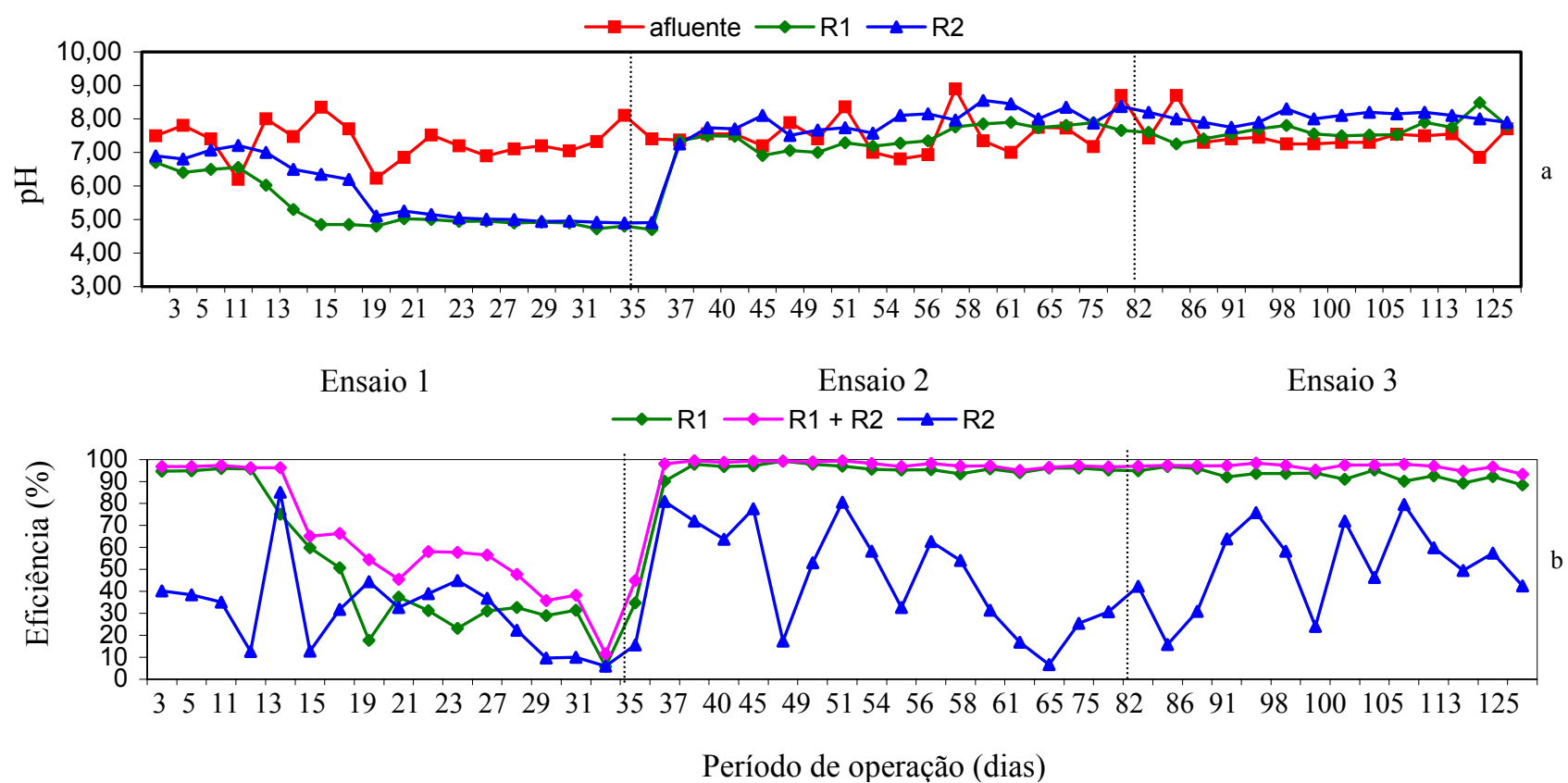

FIGURA 3. Valores de pH (a) e eficiência de remoção de DQO total (b) nos reatores R1 e R2, e no conjunto de reatores UASB, em dois estágios (R1+R2), nos ensaios 1; 2 e 3. pH values (a) and removal efficiencies of total chemical oxygen demand (total COD) (b) in the reactors $R 1$ and $R 2$, and in the set of UASB reactors in two stages $(\mathrm{R} 1+\mathrm{R} 2)$, in the trials $1 ; 2$ and 3 .

Os distúrbios ocorridos no ensaio 1 podem estar relacionados à dificuldade de acomodação dos aumentos da carga orgânica volumétrica (COV) e da carga orgânica no lodo (COL) e/ou à nãoadaptação do lodo de inóculo à água residuária durante a partida.

No início da partida no R1, o valor médio da COV foi de 3,8 g DQO total ( $\mathrm{L} \mathrm{d})^{-1}$, e o da COL, de $0,17 \mathrm{~g}$ DQO total $(\mathrm{g} \mathrm{SV} \mathrm{d})^{-1}$. Mesmo aplicando TDH baixo, de 4 dias, ocorreu acréscimo acentuado de COV e de COL a partir do $15^{\circ}$ dia do ensaio 1 , em virtude do aumento contínuo da DQO total do afluente (Figura 2a), promovido pelo aumento da fração orgânica dissolvida, atingindo valores de $34.300 \mathrm{mg} \mathrm{O}_{2} \mathrm{~L}^{-1}$, resultando na aplicação de COV de 8,6 g DQO total (L d) ${ }^{-1}$ e COL de 0,39 g DQO total $\left(\mathrm{g} \mathrm{SV} \mathrm{d}^{-1}\right.$. Essa COV foi inferior à que o lodo de inóculo era submetido, de $34 \mathrm{~g}$ DQO total $(\mathrm{L} \mathrm{d})^{-1}$, no reator UASB de onde foi retirado. No entanto, deve-se destacar que estava tratando águas residuárias de suinocultura, nas quais a fração orgânica dissolvida é inferior (de 20 a 40\% da DQO total, de acordo com SANTANA \& OLIVEIRA, 2005) à observada nas águas residuárias do beneficiamento de café por via úmida (DQO ${ }_{\text {diss. }}$ acima de $75 \%$ da DQO total (Tabela2)).

CHERNICHARO (2007) recomendou COL de 0,05 a 0,15 g DQO (g SV d) ${ }^{-1}$ para a partida de reatores anaeróbios, devendo ser aumentada gradativamente em função da eficiência. Para reatores UASB tratando esgoto sanitário doméstico, COL da ordem de $0,30 \mathrm{~g}$ DQO $(\mathrm{g} \mathrm{SV} \mathrm{d})^{-1}$, durante a partida, não prejudicou a estabilidade do processo em termos de $\mathrm{pH}$ e de ácidos graxos voláteis. Durante o regime permanente, a COL pode atingir, de acordo com o tipo de afluente a ser tratado, valores em torno de $2 \mathrm{~g}$ DQO $(\mathrm{g} \mathrm{SV} \mathrm{d})^{-1}$. Assim, os valores da COL aplicados no ensaio 1 não 
foram excessivos, considerando-se o recomendado por CHERNICHARO (2007). Contudo, em águas residuárias com compostos fenólicos, há uma etapa adicional de aclimatação do lodo em relação às etapas envolvidas na partida convencional de reatores UASB (VEERESH et al., 2005).

As concentrações médias de fenóis totais no afluente foram de 80 a $97 \mathrm{mg} \mathrm{L}^{-1}$, valores esses bastante acima do permitido para lançamento de efluentes, o qual é de $0,5 \mathrm{mg} \mathrm{L}^{-1}$, segundo a Resolução 357 do CONAMA (BRASIL, 2005). Entretanto, considerando-se que a concentração de fenóis para reduzir $50 \%$ da produção de gás de culturas não-aclimatadas de arquéias metanogênicas acetotróficas é de $2.100 \mathrm{mg} \mathrm{L}^{-1}$ (BLUM \& SPEECE, 1991), os valores encontrados no afluente foram baixos. VEERESH et al. (2005) concluíram que os fenóis, mesmo em altas concentrações, podem ser degradados em reatores UASB utilizando-se de estratégias de operação. Com a recirculação do efluente nas proporções de 1:1 e 3:1, concentrações de fenóis de 1.260 e $3.000 \mathrm{mg} \mathrm{L}^{-1}$, respectivamente, foram reduzidas com eficiências de remoção acima de $97 \%$. Com $1.000 \mathrm{mg} \mathrm{L}^{-1}$ de glicose, como co-substrato, e concentração de fenóis de $1.260 \mathrm{mg} \mathrm{L}^{-1}$, foram observadas remoções de fenóis de $98 \%$ e de DQO de $92 \%$.

No ensaio 1, foram verificados acréscimos nas concentrações de fenóis totais no afluente (Figura 4), acompanhando o aumento da DQO, e nos efluentes dos reatores R1 e R2 (35 e $23 \mathrm{mg} \mathrm{L}^{-1}$, respectivamente), indicando aumento da carga e acúmulo de compostos tóxicos, intensificando as condições que provocaram o colapso. $\mathrm{O}$ fenol, mesmo em concentração baixa, pode ser tóxico aos microrganismos, principalmente aos não-aclimatados.

A duração da partida de reatores UASB tratando águas residuárias com compostos fenólicos pode variar de 6 semanas até 10 meses, dependendo da procedência do inóculo e da aclimatação necessária (VEERESH et al., 2005). TAY et al. (2000 e 2001), citados por VEERESH et al. (2005), em reator UASB de $2 \mathrm{~L}$, utilizaram como inóculo lodo proveniente de digestores anaeróbios e verificaram que, com $1.000 \mathrm{mg} \mathrm{L}^{-1}$ de glicose como co-substrato no afluente com 105 a $1.260 \mathrm{mg} \mathrm{L}^{-1}$ de fenol, foi possível reduzir o período de partida e de granulação do lodo para 4 meses; sem a glicose, o período foi de 7 meses.

DUFF et al. (1995), citados por VEERESH et al. (2005), observaram que, com inóculo de lodo granulado (alimentado com glicose, ácido acético e água residuária de produção mecânica de polpa em indústria de papel), em reator UASB de $6 \mathrm{~L}$ com TDH de 3 dias, COV de 0,4 g DQO (L d) ${ }^{-1}$, COL de $30 \mathrm{mg}$ DQO (g SSV d) ${ }^{-1}$ e concentrações de fenóis de $500 \mathrm{mg} \mathrm{L}^{-1}$, a aclimatação ocorreu após 46 dias com remoções de DQO de até 100\%. FANG et al. (1996) utilizaram como inóculo lodo parcialmente granulado de reator UASB alimentado com glicose e verificaram que, em reator UASB de 2,8 L, com concentração de fenóis de $420 \mathrm{mg} \mathrm{L}^{-1}$, TDH de $8 \mathrm{~h}$ e COV de $3 \mathrm{~g}$ DQO total $(\mathrm{L} \mathrm{d})^{-1}$, o período de aclimatação foi de 45 dias para atingir remoções acima de $83 \%$. Dessa forma, no ensaio 1, mesmo utilizando lodo granulado como inóculo, não houve tempo para a aclimatação do lodo, mesmo com baixas concentrações de fenóis no afluente.

Além disso, no ensaio 1 , a COV média foi de $5,8 \mathrm{~g}$ DQO $(\mathrm{L} \mathrm{d})^{-1}$ e, após o $15^{\circ}$ dia, atingiu valores de até $8,6 \mathrm{~g}$ DQO total $(\mathrm{L} \mathrm{d})^{-1}$, o que pode ter limitado a remoção dos fenóis. FANG et al. (1996 e 2004) concluíram que o fenol na água residuária sintética, em concentrações de 420 a $1.260 \mathrm{mg} \mathrm{L}^{-1}$, foi efetivamente degradado em reatores UASB com COV de até $6 \mathrm{~g}$ DQO total $(\mathrm{L} \mathrm{d})^{-1}$ e temperaturas de 37 e $26{ }^{\circ} \mathrm{C}$. O aumento da COV para 7 a 18 g DQO total $(\mathrm{L} \mathrm{d})^{-1}$, por meio de maiores concentrações de fenóis no afluente ou diminuição do $\mathrm{TDH}$, provocou decréscimos acentuados na remoção de fenóis.

No sistema de tratamento com os reatores UASB em dois estágios, a maior eficiência média de remoção de fenóis, de $90 \%$, e com concentração média no efluente, de $10 \mathrm{mg} \mathrm{L}^{-1}$, ocorreu no ensaio 2, com COV de 3,6 g DQO (L d) ${ }^{-1}$ no R1. LUIZ et al. (2004) trataram águas residuárias de despolpamento de café em um reator UASB de 11,7 L, com TDH de $69 \mathrm{~h}$ e COV de 1,12 g DQO $(\mathrm{L} \mathrm{d})^{-1}$, e obtiveram $82 \%$ de remoção de fenóis.

$\mathrm{Na}$ Figura 2b, pode ser constatado o colapso dos reatores R1 e R2 no ensaio 1. Com o aumento da DQO total do efluente no decorrer da operação, a eficiência de remoção de DQO 
diminuiu continuamente (Tabela 3 e Figura 3b), provocando a interrupção do ensaio 1 aos 35 dias, quando as remoções eram praticamente nulas, e o lodo apresentava aspecto de deteriorado.
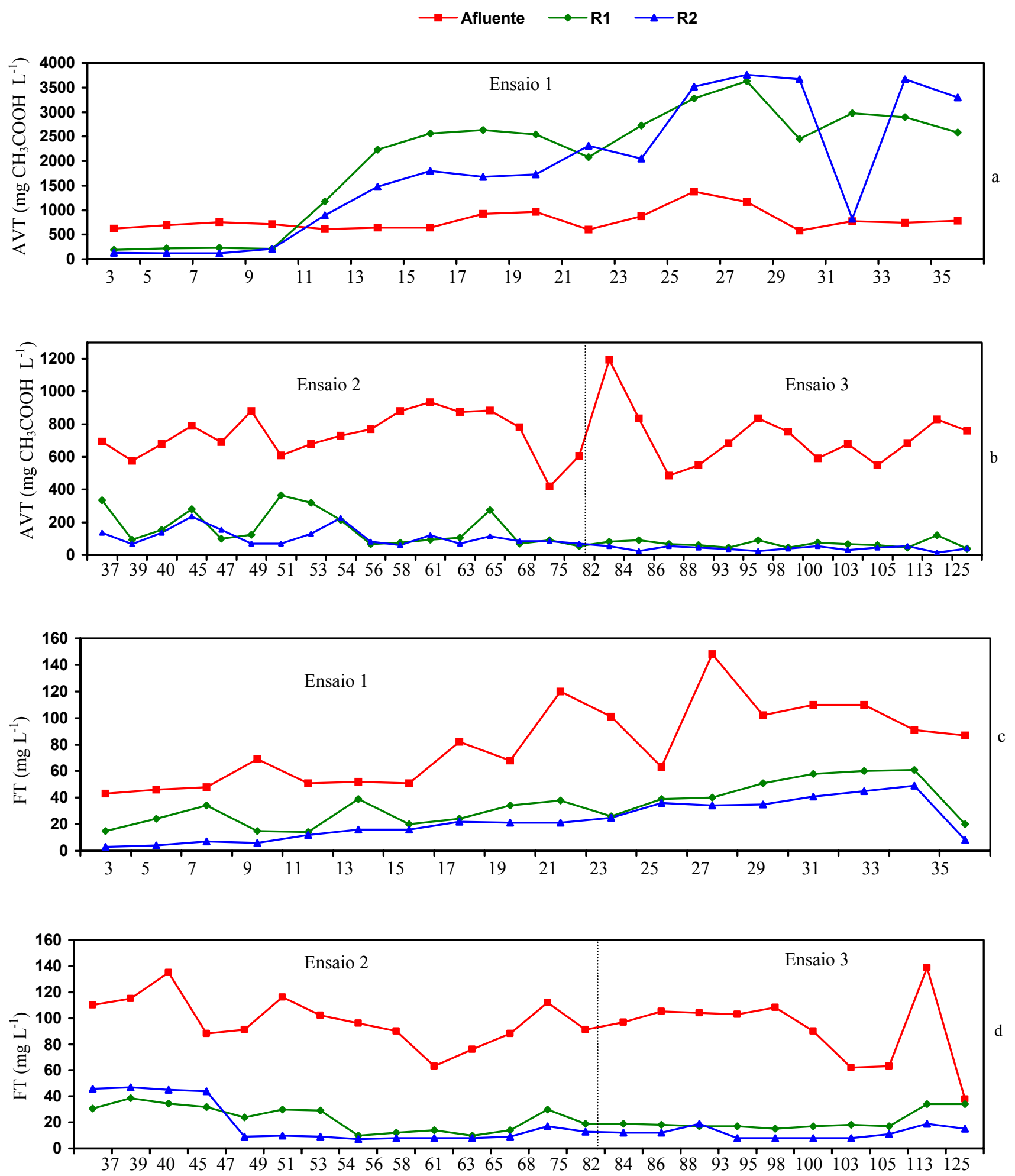

Período de operação (dias)

FIGURA 4. Concentrações de ácidos voláteis totais (AVT), no ensaio 1 (a) e nos ensaios 2 e 3 (b), fenóis totais (FT), no ensaio 1 (c) e nos ensaios 2 e 3 (d), no afluente e nos efluentes dos reatores UASB (R1 e R2), em dois estágios. Concentrations of total volatile acids (TVA) in the trial 1 (a) and in the trials 2 and 3 (b), total phenols (TP) in the trial 1 (c) and in the trials 2 and 3 (d), in the affluent and effluents of UASB reactors $(R 1$ and $R 2)$ in two stages. 
No ensaio 2, os reatores 1 e 2 foram reinoculados com lodo da mesma procedência do utilizado no ensaio 1 e com concentração de sólidos voláteis de 46,2 $\mathrm{g} \mathrm{L}^{-1}$. O TDH foi aumentado para 6,2 dias, aplicando-se COV de 3,2 a 5,7 g DQO total (L d ${ }^{-1}$ e COL de 0,14 a 0,24 g DQO total $(\mathrm{g} \mathrm{SV} \mathrm{d})^{-1}$ no R1, durante os 10 dias iniciais. Em seguida, os valores de DQO total do afluente diminuíram continuamente (Figura 2c), resultando na aplicação de COV de 1,5 a 2,5 g DQO total $(\mathrm{L} \mathrm{d})^{-1}$ no R1.

Nessas condições, o sistema de tratamento com os reatores UASB em dois estágios (R1+R2), manteve-se estável, com valores médios de eficiência de remoção de 95 a $98 \%$ para DQO total, DQO $_{\text {diss, }}$ SST e SSV, e de $90 \%$ para fenóis totais, com coeficientes de variação (C.V.) de 1 a $4 \%$ (Tabela 3). No ensaio 3, com TDH de 5,2 dias e COV de 3,0 g DQO total (L d) ${ }^{-1}$, a estabilidade

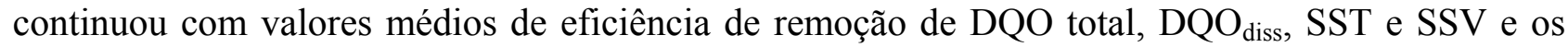
respectivos CVs similares aos obtidos no ensaio 2 (Tabela 3). Para os fenóis totais, ocorreu diminuição da eficiência média de remoção para $86 \%$ e aumento do C.V. para $11 \%$. Esses resultados mantiveram-se a partir do $5^{-}$dia do ensaio 2 até o final do ensaio 3 , indicando que as condições impostas aos reatores R1 e R2 foram representativas de regime estável com altas eficiências de remoção. As maiores remoções ocorreram no R1, mas houve contribuição do R2 para melhorar a estabilidade e elevar as remoções, principalmente de SST, SSV e fenóis totais.

SILVA \& CAMPOS (2005), tratando águas residuárias de beneficiamento de café por via úmida, com DQO total em torno de $3.250 \mathrm{mg} \mathrm{L}^{-1}$, em reator UASB, em escala de bancada $(11,7 \mathrm{~L})$, com TDH de $69 \mathrm{~h}$ e COV de $0,59 \mathrm{~g}$ DQO $(\mathrm{L} \mathrm{d})^{-1}$, obtiveram eficiência de remoção de DQO total de 78\%. BELLO MENDOZA \& CASTILLO-RIVERA (1998) utilizaram reator anaeróbio híbrido (UASB/filtro), com o afluente com DQO média de $2.480 \mathrm{mg} \mathrm{L}^{-1}$, e verificaram remoção de DQO de $77 \%$, aplicando COV de 1,89 g DQO (L d) ${ }^{-1}$ com TDH de $22 \mathrm{~h}$. O aumento da COV para valores em torno de 2,40 g DQO $(\mathrm{L} \mathrm{d})^{-1}$ provocou queda acentuada na eficiência. A recuperação do reator do choque de carga orgânica ocorreu após uma semana de operação. Nos ensaios 2 e 3, os valores de eficiência de remoção de DQO foram significativamente superiores e estáveis, aplicando-se COV maiores e com águas residuárias brutas, com DQO total de 4.000 a $36.000 \mathrm{mg} \mathrm{O}_{2} \mathrm{~L}^{-1}$. Os maiores valores de TDH e o uso do sistema de tratamento anaeróbio, em dois estágios, com os reatores UASB, contribuíram para os melhores resultados

No ensaio 1, as concentrações médias de ácidos voláteis totais (AVT) nos efluentes dos reatores R1 e R2 atingiram valores de 2.035 e $1.840 \mathrm{mg} \mathrm{CH}_{3} \mathrm{COOH} \mathrm{L}{ }^{-1}$ (Tabela 4), respectivamente, os quais estão acima do recomendado para a operação estável e a manutenção da atividade da microbiota nos reatores anaeróbios, provocando a acidificação dos mesmos. Com a redução da COV para valores médios de 3,6 e 3,0 g DQO total $(\mathrm{L} \mathrm{d})^{-1}$, nos ensaios 2 e 3, respectivamente, a concentração de AVT nos efluentes dos reatores R1 e R2 manteve-se abaixo de $200 \mathrm{mg} \mathrm{CH}_{3} \mathrm{COOH} \mathrm{L}^{-1}$ (Figura $4 \mathrm{~b}$ ), a qual é adequada para a operação estável de reatores UASB tratando esgotos sanitários domésticos, segundo LETTINGA \& HULSHOFF-POL (1991). GERARDI (2003) citou que as concentrações adequadas de AVT nos reatores anaeróbios são de 50 a $200 \mathrm{mg} \mathrm{CH}_{3} \mathrm{COOH} \mathrm{L}{ }^{-1}$, no primeiro estágio, e de 50 a $500 \mathrm{mg} \mathrm{CH}_{3} \mathrm{COOH} \mathrm{L}^{-1}$, no segundo estágio.

As percentagens de metano no biogás, nos reatores R1 e R2, foram de $69 ; 88$ e $89 \%$ e de 52; 69 e $73 \%$, respectivamente, nos ensaios $1 ; 2$ e 3 . As maiores produções volumétricas e específicas de metano ocorreram nos ensaios 2 e 3, com as menores $\left.\operatorname{COV}(3,0 \text { e 3,6 g DQO total (L d })^{-1}\right)$, e foram de 0,483 e $0,453 \mathrm{~L} \mathrm{CH}_{4}\left(\mathrm{~L}\right.$ reator d) ${ }^{-1}$ e 0,147 e $0,190 \mathrm{~L} \mathrm{CH}_{4}\left(\mathrm{~g}\right.$ DQO total removida) ${ }^{-1}$, respectivamente, no sistema de tratamento com os reatores UASB em dois estágios (R1+R2) (Tabela 5). No ensaio 1, ocorreu a menor produção volumétrica média de metano de 0,286 $\mathrm{L} \mathrm{CH}_{4}$ $(\mathrm{L} \text { reator } \mathrm{d})^{-1}$, nos reatores UASB, em dois estágios $(\mathrm{R} 1+\mathrm{R} 2)$. Em virtude da acidificação dos reatores no ensaio 1, a estabilidade dos mesmos foi comprometida, acarretando decréscimo na produção de metano, pois os reatores foram operados numa faixa de $\mathrm{pH}$ e AVT desfavorável à atividade das arquéias metanogênicas. 
TABELA 5. Valores médios e coeficientes de variação (C.V. \%) da produção diária de biogás, da percentagem de metano no biogás, e das produções volumétrica e específica de metano durante a operação dos reatores UASB (R1 e R2), em dois estágios, nos ensaios 1; 2 e 3. Average values and variation coefficients (VC in \%) of the daily production of biogas, methane percentage in biogas and volumetric and specific productions of methane during the operation of UASB reactors (R1 and R2) in two stages, in the trials $1 ; 2$ and 3.

\begin{tabular}{|c|c|c|c|c|c|c|c|c|c|c|c|c|c|}
\hline \multirow{3}{*}{ Ensaio } & \multirow{2}{*}{\multicolumn{2}{|c|}{$\begin{array}{l}\mathrm{CH}_{4} \\
(\%)\end{array}$}} & \multirow{2}{*}{\multicolumn{3}{|c|}{$\begin{array}{l}\text { Produção Diária de Biogás } \\
\qquad\left(\mathrm{L} \mathrm{d}^{-1}\right)\end{array}$}} & \multirow{2}{*}{\multicolumn{3}{|c|}{$\begin{array}{l}\text { Produção Volumétrica } \\
\mathrm{L} \mathrm{CH}_{4}\left(\mathrm{~L} \text { reator d }{ }^{-1}\right)\end{array}$}} & \multicolumn{5}{|c|}{$\begin{array}{c}\text { Produção Específica } \\
\left(\mathrm{L} \mathrm{CH}_{4}(\mathrm{~g} \text { DQO total })^{-1}\right)\end{array}$} \\
\hline & & & & & & & & & \multicolumn{2}{|c|}{ Adicionada } & \multicolumn{3}{|c|}{ Removida } \\
\hline & R1 & $\mathrm{R} 2$ & R1 & $\mathrm{R} 2$ & $\mathrm{R} 1+\mathrm{R} 2$ & $\mathrm{R} 1$ & $\mathrm{R} 2$ & $\mathrm{R} 1+\mathrm{R} 2$ & R1 & $\mathrm{R} 2$ & $\mathrm{R} 1$ & R2 & $\mathrm{R} 1+\mathrm{R} 2$ \\
\hline 1 & 69 & 52 & 12,1 & 0,43 & 12,5 & 0,417 & 0,023 & 0,286 & 0,089 & 0,022 & 0,145 & 0,029 & 0,125 \\
\hline 2 & 88 & 69 & 16,1 & 0,45 & 16,5 & 0,708 & 0,031 & 0,483 & 0,166 & 0,125 & 0,141 & 0,169 & 0,147 \\
\hline 3 & 89 & 73 & 14,9 & 0,44 & 15,4 & 0,663 & 0,032 & 0,453 & 0,173 & 0,078 & 0,193 & 0,128 & 0,190 \\
\hline \multirow{3}{*}{$\begin{array}{l}\mathrm{CV} \\
\%\end{array}$} & 86 & 91 & 13 & 21 & 15 & 24 & 23 & 21 & 40 & 94 & 74 & 80 & 79 \\
\hline & 31 & 40 & 75 & 10 & 22 & 20 & 10 & 14 & 38 & 33 & 39 & 46 & 43 \\
\hline & 32 & 42 & 21 & 11 & 16 & 20 & 11 & 15 & 36 & 24 & 38 & 35 & 36 \\
\hline
\end{tabular}

BELLO-MENDOZA \& CASTILLO-RIVERA (1998) citaram que POTRES \& CALZADA (1990) e VINAS et al. (1988), tratando águas residuárias do beneficiamento de café por via úmida em reatores anaeróbios híbridos (UASB/ filtro de $\left.10,5 \mathrm{~m}^{3}\right)$ e UASB $(20 \mathrm{~L})$ com COV de 2,2 e 15,0 g DQO $(\mathrm{L} \mathrm{d})^{-1}$, obtiveram remoções de DQO de 75 a $80 \%$ e de $55 \%$, e produções de biogás de 0,34 e 5,09 L $(\mathrm{L} \mathrm{d})^{-1}$, respectivamente. Dessa forma, verifica-se que o aumento da produção de metano em reatores UASB, em dois estágios, tratando águas residuárias do beneficiamento de café por via úmida, está relacionada com acréscimos na COV aplicada em condições de estabilidade, conforme pôde ser observado nos ensaios 2 e 3, e comparando-se com as produções de biogás citadas por BELLO-MENDOZA \& CASTILLO-RIVERA (1998).

\section{CONCLUSÕES}

Utilizando o sistema de tratamento com os reatores anaeróbios de fluxo ascendente com manta de lodo (UASB), em dois estágios, foi possível obter eficiências de remoção de DQO e sólidos suspensos estáveis e elevadas, acima de 95\%, e produções de metano em torno de $0,5 \mathrm{~L}(\mathrm{Ld})^{-1}$ com COV média de 3,0 e 3,6 g DQO $(\mathrm{L} \mathrm{d})^{-1}$, e TDH de 5,2 e 6,2 dias no primeiro reator, tratando águas residuárias do beneficiamento de café por via úmida com DQO de 4.000 a $36.000 \mathrm{mg} \mathrm{O}_{2} \mathrm{~L}^{-1}$, fenóis totais de 40 a $150 \mathrm{mg} \mathrm{L}^{-1}$ e $\mathrm{pH}$ de 7,3 a 7,6, ajustado com $\mathrm{NaOH}$. Nessas condições, não houve toxicidade, e a remoção de fenóis foi estável, com valores médios de 86 a 90\%, indicando a viabilidade da aplicação do processo anaeróbio em dois estágios.

A utilização do segundo reator, instalado em série, foi importante para manter as altas eficiências de remoção estáveis, principalmente quando ocorreram oscilações no primeiro reator.

\section{AGRADECIMENTOS}

À CAPES e à Tigre S.A., pelo apoio financeiro.

\section{REFERÊNCIAS}

APHA, AWWA, WPCF. Standart methods for the examination of water and wastewater. $20^{\text {th }}$ ed. Washington: American Public Health Association , 1998. 1.268 p.

BELLO-MENDOZA, R.; CASTILLO-RIVERA, M.F. Start-up of an anaerobic hybrid (UASB/filter) reactor treating wastewater from a coffee processing plant. Anaerobe, London, v.4, n.5, p.219-25, 1998. 
BLUM, D.J.; SPEECE, R.E. A database of chemical toxicity to environmental bacteria and its use in interspecies comparisons and correlations. Research Journal of Water Pollution Control Federations, Alexandria, v. 63, n. 3, p. 198-207, 1991.

BOUALLAGUI, H.; TORRIJOS, M.; GODON, J.J.; MOLETTA, R. Two-phases anaerobic digestion of fruit and vegetables wastes: bioreactors performance. Biochemichal Engineering Journal, Rickmanswort, v.39, n.21, p.193-7, 2004.

BRASIL. Resolução nº 357, 17-3-2005. Dispõe sobre a classificação dos corpos de águas e diretrizes ambientais para o seu enquadramento, bem como estabelece as condições e padrões de lançamento de efluentes, e dá outras providências. Brasília: CONAMA, 2005. 23 p.

CHERNICHARO, C.A.L. de. Princípios do tratamento biológico de águas residuárias: reatores anaeróbios. Belo Horizonte: Departamento de Engenharia Sanitária e Ambiental, Universidade Federal de Minas Gerais, 2007. v.5, 379 p.

DILALLO, R.; ALBERTSON, O.E. Volatile acids by direct titration. Journal of Water Pollution Control Federation, Alexandria, v.33, n.4, p.356-65, 1961.

FANG, H.H.P.; CHEN, T.; LI, Y.; CHUI, H. Degradation of phenol in wastewater in an upflow anaerobic sludge blanket reactor. Water Research, Oxford, v.30, n.6, p.1.353-60, 1996.

FANG, H.H.P.; LIU, Y.; KE, S.Z.; ZHANG, T. Anaerobic degradation of phenol in wastewater at ambient temperature. Water Science and Technology, London, v.49, n.1, p.95-102, 2004.

GERARDI, M.H. The microbiology of anaerobic digesters. Chichester: John Wiley, 2003. 165 p.

HAANDEL, A.C. Van; LETTINGA, G. Anaerobic sewage treatment: a pratical guide for regions with a hot climate. Chichester: John Wiley, 1994. 226 p.

HAANDEL, A.C. Van; CAVALCANTI, P.F.F.; MEDEIROS, E.J.S.; SILVA, J.K.M. Excess sludge discharge frequency for UASB reactors. Water Science and Technology, Oxford, v.40, n.8, p.211-19, 1999.

IBGE. FUNDAÇÃO INSTITUTO BRASILEIRO DE GEOGRAFIA E ESTATÍSTICA. Disponível: http://sidra.ibge.gov.br. Acesso em: 15 out. 2006.

LETTINGA, G.; HULSHOFF-POL, L.W. UASB: process design for various types of wastewater. Water Science and Technology, Oxford, v.24, n.8, p.87-107, 1991.

LO MÔNACO, P.A.; MATOS, A.T.; MARTINEZ, M.A.; JORDÃO, C.P. Eficiência de materiais orgânicos filtrantes no tratamento de águas residuárias da lavagem e despolpa dos frutos do cafeeiro. Engenharia na Agricultura, Viçosa, v.10, n.1-4, p.40-7, 2002.

LUIZ, F.A.R.; CAMPOS, C.M.M.; CARMO, A.C. Partida de um reator UASB em escala laboratorial tratando efluente líquido proveniente do despolpamento do café. In: CONGRESSO BRASILEIRO DE ENGENHARIA AGRICOLA, 33., 2004, São Pedro. Anais... Campinas: Associação Brasileira de Engenharia Agrícola, 2004. 1 CD-ROM.

MATOS, A.T.; LO MÔNACO, P.A. Tratamento e aproveitamento agrícola de resíduos sólidos e líquidos da lavagem e despolpa dos frutos do cafeeiro. Viçosa-MG: UFV, 2003. 68 p. (Boletim Técnico, 7).

METCALF \& EDDY. Wastewater Engineering: treatment and reuse. $4^{\text {th }}$ ed. New York: McGrawHill, 2003. 1.819 p.

PINTO, A.B. Avaliação de gramíneas forrageiras com uso de águas residuárias da lavagem de frutos do cafeeiro em rampas de tratamento. 2001. 108 f. Dissertação (Mestrado em Engenharia Agrícola) - Universidade Federal de Viçosa, Viçosa, 2001.

PULGARIN, C.; SCHWITZGUEBEL, J.P.; TABACCHI, R. Utilization of wastes from coffee production. Biofuture, Lausanne, n.102, p.43-50, 1991. 
SANTANA, A.M. de; OLIVEIRA, R.A. de. Desempenho de reatores anaeróbios de fluxo ascendente com manta de lodo em dois estágios tratando águas residuárias de suinocultura. Engenharia Agrícola, Jaboticabal, v.25, n.3, p.817-30, 2005.

SHAHIDI, F.; NACZK, M. Food Phenolics: sources, chemistry, effects and aplications. Basel: Technomic Publishing, 1995. 331 p.

SILVA, B.A.; CAMPOS, C.M.M. Tratamento anaeróbio de efluentes líquidos gerados no beneficiamento úmido do café. In. CONGRESSO BRASILEIRO DE ENGENHARIA AGRÍCOLA, 34., 2005, Canoas. Anais... Jaboticabal: Associação Brasileira de Engenharia Agrícola, 2005. 1 CDROM.

SPEECE, R. E. Anaerobic biotecnology for industrial wastewaters. Nashville: Archae Press, 1996. $394 \mathrm{p}$.

VEERESH, G.S.; KUMAR, P.; MEHROTA, I. Treatment of phenol and cresol in upflow anaerobic sludge blanket (UASB) process: a review. Water Research, Oxford, v.39, p.154-70, 2005.

ZAMBRANO, F.D.A.; ISAZA, H.J.D. Demanda química de oxigeno e nitrógeno total de los subproductos del proceso tradicional de beneficio húmedo del café. Revista del Centro Nacional de Investigaciones de Café - Cenicafé, Chinchiná, v.49 n.4, p.279-89, 1998. 